\title{
MARKET TIMING WITH THE ANALYTICAL NETWORK PROCESS
}

\author{
Andreas Neuhierl, ${ }^{* *}$ \\ University of Augsburg, Department of Statistics and Mathematical Economic Theory \\ Augsburg, Germany \\ andreas.neuhierl@wiwi.uni-augsburg.de \\ Hartmut Hofrichter \\ IDS GmbH - Analysis and Reporting Services \\ Munich, Germany \\ Hartmut.Hofrichter@ids.allianz.com
}

\begin{abstract}
In this paper we develop a stock market timing model based on expert judgments and observable market valuation and sentiment indicators. We apply it to the US stock market. We use the model for monthly, weekly and daily timing decisions over the period from 1994 to 2008. Two different strategies are used: switching between holding the market index and holding cash as well as holding the index and going short. In the case of monthly timing, a buy and hold strategy would have delivered a return of $4.5 \%$, the best ANP timing model on a monthly basis delivered a return of $8.4 \%$ (long-cash) and $8.5 \%$ (long-short); on a weekly basis $8.1 \%$ (long-cash) and 6.5\% (long-short); on a daily basis $14.4 \%$ (long-cash) and 19.2\% (long-short). In the daily case we apply White's Reality Check for data snooping and Hansen's test for superior predictive ability (SPA) and for the case of long-cash we find genuine outperformance even while adjusting for data snooping.
\end{abstract}

Keywords: Market Timing, Financial Crisis Probability, Data Snooping

\section{Introduction}

It has long been the goal of many investors to find methods and models for timing the stock market. The strategy is intuitive and appealing: invest in the stock market when the market is expected to go up and hold cash or go short, when the market is expected to fall. Shilling (1992) found that invetors could have boosted their returns from $11.2 \%$ to $19.0 \%$ per annum during the period from 1946 to 1991, just by avoiding exposure to the 50 worst months.

If markets were efficient the task of market timing would surely be useless and it would be impossible to beat a buy-and-hold strategy. For this reason, market timing rules usually build on empirical findings rather than theoretical models. In this area, it is common to use well-known indicators, such as the priceearnings ratio (Campbell and Shiller, 1988b and 2000) or the dividend yield (Shiller, 1984), (Fama and French, 1988) and various other indicators. From a methodological point of view, OLS regression is usually the tool of choice to generate predictions.

By now there is a large body of literature that investigates the profitability of market timing rules. Fisher and Statman (2006a and 2006b) investigate the profitability of timing strategies derived from financial indicators. Shen (2003) finds that the difference between the price-earnings ratio and various interest rates

\footnotetext{
* Corresponding author.

${ }^{* *}$ The authors are grateful to Christian Heumann from the University of Munich for valuable suggestions and to the members of the research team at ATACAMA Capital GmbH for fruitful discussions and their hospitality.
} 
is useful for market timing. The potential of interest rates alone is investigated by Breen, Lawrence and Jagannath (1989) and Prather and Bertin (1997 and 1998). Copeland and Copeland (1999) analyse the use of an implied volatility index for market timing decision. All of these studies usually use one or two indicators for deriving a timing signal. In this paper, we take a different approach and build a market timing model based on the Analytical Network Process (ANP). In order to derive market timing decisions, we use expert knowledge as well as observable financial indicators, many of which have been applied in isolation. In the awareness of possible data snooping biases, we use White's Reality Check (White, 2000) and Hansen's test for superior predictive ability (Hansen, 2005).

The remainder of the paper is organized as follows: Section 2 provides a short introduction to the analytical network process, Section 3 describes the ANP timing model, i.e. the indicators that are employed as well as the mapping from observed values to 1-9 scores. In Section 4 we present the empirical results of our backtests and conclude with suggestions for further research in Section 5.

\section{The Analytical Network Process}

Developing our market timing strategy is based on the enhanced method of the Analytic Hierarchy Process (AHP), containing feedback and inner dependencies, namely the Analytic Network Process (ANP). A process relating to expert judgment that is able to reflect statistically immeasurable connections. In a system of $n$ components with feedback and dependencies, every component can interact with other components or even influence itself. The system of components $\left\{C_{a}, \ldots, C_{n}\right\}$ and the linkage $L=\left\{\left(C_{a}, C_{a}\right),\left(C_{a}, C_{b}\right), \ldots,\left(C_{n}, C_{n}\right)\right\}$ between them forms the network structure, c.f. Niemira and Saaty (2004). This network is essential to obtain reliable weights for each component in the network, the basic idea of the ANP multicriteria decision making model.

The derivation of the weights for all $n$ components $C_{n}$ is based on expert judgments regarding the dependencies in relevance to an overall criterion. In our case, of financial market analysis this criteria is the contribution to a financial crisis. These judgments value pairwise comparison of linked components by using the 1-9 scale (Table 1) from Saaty (1977). Detailed observations of scale performance and comparisons to various types of scales can be found in Saaty (1980), which affirmed that the 1-9 scale is ideal for the ANP. For more detailed inspection of the scale performance see Harker and Vargas (1987).

Table 1: Scale of Relative Importance

\begin{tabular}{|c|c|c|}
\hline $\begin{array}{l}\text { Intensity of } \\
\text { Importance }\end{array}$ & Definition & Explanation \\
\hline 1 & Equal importance & Two activities contribute equally to the objective \\
\hline 2 & Weak or slight & \\
\hline 3 & Moderate importance & $\begin{array}{l}\text { Experience and judgment slightly favor one activity over } \\
\text { another }\end{array}$ \\
\hline 4 & Moderate plus & \\
\hline 5 & Strong importance & $\begin{array}{l}\text { Experience and judgment strongly favor one activity over } \\
\text { another }\end{array}$ \\
\hline 6 & Strong plus & \\
\hline 7 & $\begin{array}{lc}\text { Very strong or } \\
\text { demonstrated importance }\end{array}$ & $\begin{array}{l}\text { An activity is favored very strongly over another; its } \\
\text { dominance demonstrated in practice }\end{array}$ \\
\hline 8 & Very, very strong & \\
\hline 9 & Extreme importance & $\begin{array}{l}\text { The evidence favoring one activity over another is of the } \\
\text { highest possible order or affirmation }\end{array}$ \\
\hline
\end{tabular}

In order to justify the scale and derive weights, it is necessary to rely on basic axioms: 
1. Weights belong to the closed interval $[0,1]$

2. Every ratio for $\left\{C_{a}, C_{b}\right\}$ assigned by an expert's judgment enforces a reciprocal value for $\left\{C_{b}, C_{a}\right\}$

3. Homogeneity exists to allow computations of the priorities after the expert judgments

The mathematical combination of the network structure and expert's pairwise comparisons is done by using a matrix approach, which delivers the Supermatrix $\mathbf{W}$. To create the Supermatrix for a network system, it is assumed that there are $N$ clusters, denoted by $C_{h}, h=1, \ldots, N$. Each cluster $C_{h}$ has $n_{h}$ elements: $e_{h_{1}}, e_{h_{2}}, \ldots, e_{h_{h_{h}}}$.

It is a complete system of clusters $\left\{C_{a}, \ldots, C_{N}\right\}$ and their weights $W_{i j}$.

$$
\mathbf{W}=\begin{gathered}
\mathrm{C}_{1} \\
\mathrm{C}_{2} \\
\vdots \\
\mathrm{C}_{\mathrm{N}}
\end{gathered}\left(\begin{array}{cccc}
\mathbf{W}_{11} & \mathbf{W}_{12} & \cdots & \mathbf{W}_{1 \mathrm{~N}} \\
\mathbf{W}_{21} & \mathbf{W}_{22} & \cdots & \mathbf{W}_{2 \mathrm{~N}} \\
& \vdots & \ddots & \\
\mathbf{W}_{\mathrm{N} 1} & \mathbf{W}_{\mathrm{N} 2} & & \mathbf{W}_{\mathrm{NN}}
\end{array}\right)
$$

The entry $\mathbf{W}_{\mathbf{i j}}$ is called a block of the Supermatrix, with the form:

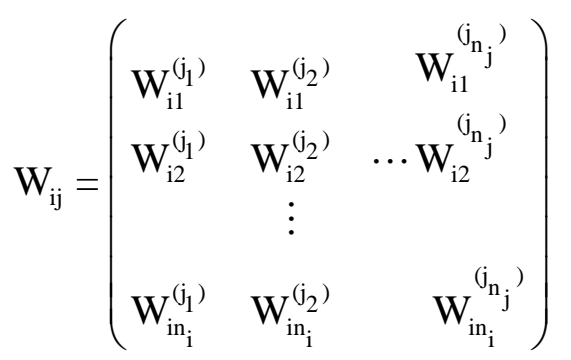

The columns of these $\mathbf{W}_{\mathbf{i j}}$ are principal eigenvectors of the influence of the elements in the $i$-th component on the elements in the $j$-th component.

From pairwise comparisons a priority vector is obtained that represents the impact of a given set of elements on another element or component in the network. In the case of no connection between elements or components a value of zero is assigned to their comparison like suggested by Saaty (2004). The basic intention of employing the Supermatrix was to develop a way in which these derived vectors are combined to one system. By containing influences of elements on themselves or components influences on other components, Saaty and Vargas (2006) show that the Supermatrix represents all connections of the network in one system. To develop a priority vector for the complete network system by using the Supermatrix demand further computation. Each column of the Supermatrix includes several priority vectors with different priority elements. Synthesizing these various priority vectors is necessary to receive an overall priority vector for the complete Supermatrix. This is done by normalizing the matrix and multiplying it by itself to obtain the limit of the Supermatrix. Normalizing the Supermatrix means to create a stochastic matrix. The multiplication of a matrix with itself is also known as raising the matrix to powers.

$$
\lim _{k \rightarrow \infty} \mathbf{W}^{k}
$$

This delivers the global priority vector which can be used to gain the weights of all components and elements. 


\section{The ANP Timing Model and Inference}

To develop a market timing strategy based on financial crisis probability, it is necessary build a predictive model of financial crises. Since the ANP creates static results, variation over time needs special implementation. Historical data analysis is used to build a time varying model that reflects changes in value of basic market indicators. These indicators will be merged into a network system to use the ANP. Combined with results of data analysis, financial crisis probability that will serve as threshold for market timing strategies is computed.

\subsection{Indicators}

For obtaining useful indicators for construction of a timing model based on the ANP we resort to the financial literature. The financial literature offers a large number of papers about indicators that have been employed for market timing. In the following sections we will shortly describe the indicators employed in our network model.

\subsubsection{Price-Earnings Ratio}

The price-earnings ratio (PER) is one of the most widely used ratios in the financial literature. Like many other financial ratios, it is motivated by the idea that stock prices do not wander away too much from their fundamental values, thus the PER has a tendency to be mean reverting. Among others Campbell and Shiller (1988a, 1998b and 2001) and Fama and French (1988 and 1989) argue that the PER has predictive power for future returns. Thus in our timing model a high PER will increase the probability of a sharp decline, whereas a low PER will lower the probability of a sharp decline.

\subsubsection{Put-Call Ratio}

The put-call ratio also measures investor sentiment. It is defined as the trading volume of puts relative to the trading volume of calls. When the ratio is high, i.e. the number of puts traded is significantly higher than the number of calls, the market is said to be pessimistic and vice versa. Fisher and Statman (2000) do not use the put-call ratio directly, but stress the importance of sentiment indicators for investment strategies.

\subsubsection{Credit Spread}

The credit spread measures investors' trust in the future profitability of companies. Fama and French (1989) document that the difference in yields between BAA-rated and a AAA-rated corporate bonds has valuable information for predicting future returns. An increase in the credit spread indicates high risk aversion and thus increases the probability of a sharp decline of the market.

\subsubsection{Term Spread}

In our case the term spread is calculated as the difference between the yield of a 10-year government bond and a 3-month Treausury Bill. In general, the term structure of interest rates may contain useful information about future economic activity and expected inflation e.g. Mishkin (1990). In the context of financial markets, the term spread has shown to be useful to predict future returns, c.f. Campbell (1987) and Fama and French (1989).

\subsubsection{Implied Volatility}

Volatility and its implications for investment decisions have been investigated very closely in the financial literature. Since the theoretical work of Merton (1980) and an empirical investigation of French and Schwert (1987) there has been a large number of essays that investigated the value of volatility for investment decision. We will only refer to the theoretical discussion of Christoffersen and Diebold (2006) and to the applied work of Copeland and Copeland (1999) and the numerous reference therein. 


\subsubsection{Trade Volume}

The trading volume is also an indicator for the current condition of the market. If the volume is high the market is usually very nervous and a sharp decline is more likely than in the times of low volume. Naturally the volume increases with higher prices and also over time as the stock market became more and more popular.

\subsubsection{Commodity Prices}

The impact of commodity prices on future returns in the stock market is not always clear. High prices of some natural resources may help some companies. A high oil price might, for example, help some oil exploration companies whose means of exploration might be too expensive for a low oil price. On the contrary a high oil price will undoubtedly be counterproductive to most automobile manufacturers. In general, there is a tendency for high commodity prices to increase the probability of a decline in the stock market.

\subsection{Network Model}

The structure of feedback and dependencies for the financial crisis model was developed by experts of financial markets. These experts from ATACAMA Capital $\mathrm{GmbH}^{1}$ built a network model by considering any possible linkage. Figure 1 shows the final linkage. To create the network, it is necessary to merge the previous mentioned factors into homogeneous clusters. The connections between the clusters and elements lead to a set of pairwise comparisons, which were carried out by expert judges.

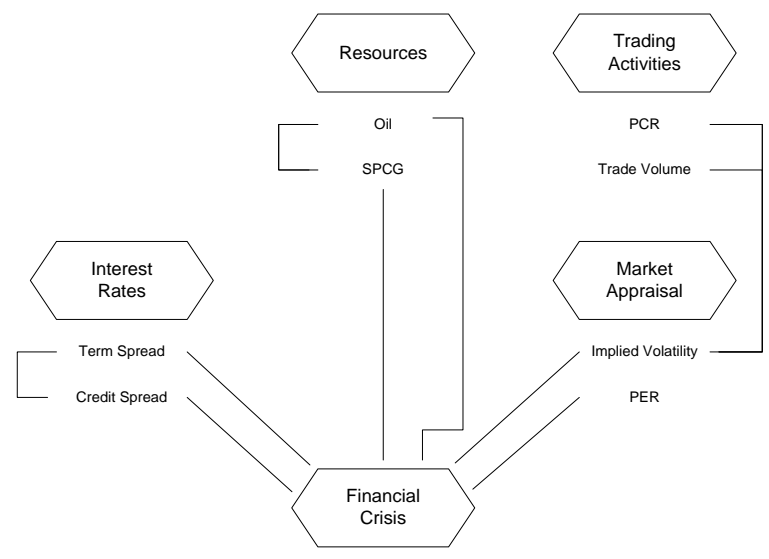

Figure 1: Connection between Market Indicators in the Financial Crisis Network

\subsection{Expert Opinions}

Expert knowledge of economics and stock markets are essential to compare the market indicators of the financial crisis network. According to the network structure, pairwise comparisons are needed for all connections to develop the Supermatrix. These comparisons, based on judgments of experts from ATACAMA Capital, are used to derive the Supermatrix. The Supermatrix can be found in the Appendix.

The Supermatrices computed by the judgments of experts can be seen in Tables 9, 10 and 11 in the Appendix. The first table contains the unweighted Supermatrix, the second table shows the weighted Supermatrix and finally the limit Supermatrix can be found in the third table. This limit Supermatrix derives a priority vector which includes the overall limiting and can be transformed to display cluster priorities. In this approach where a financial crisis is the relevant cluster, a normalization of the limiting priorities without crisis is needed to interpret the influence of the market indicators.

${ }^{1}$ www.atacap.com, an asset management company focused on innovative strategies based on financial research and market analysis 
This vector of market indicator weights, displayed in Table 1, is used in the next chapter to compute the probability of upcoming financial crisis.

Table 2: Market indicator weights

\begin{tabular}{|l|c|}
\hline Indicator & Weight \\
\hline Credit Spread & 0.34 \\
\hline Implied Volatility & 0.14 \\
\hline Oil & 0.05 \\
\hline Price-Earnings Ratio & 0.34 \\
\hline Put-Call Ratio & 0.02 \\
\hline SPGSCI & 0.02 \\
\hline Term Spread & 0.03 \\
\hline Trade Volume & 0.06 \\
\hline
\end{tabular}

Table 3: Scoring Rule for Quantiles

\begin{tabular}{|c|l|}
\hline Score & $\begin{array}{l}\text { Threshold for Lower Tail of } \\
\text { Distribution }\end{array}$ \\
\hline 1 & less $75 \%$ \\
\hline 3 & greater $^{*} 75 \%$ but less $80 \%$ \\
\hline 5 & greater $^{*} 80 \%$ but less $85 \%$ \\
\hline 7 & greater $^{*} 85 \%$ but less $90 \%$ \\
\hline 8 & greater $^{*} 90 \%$ but less $95 \%$ \\
\hline 9 & greater $^{*} 95 \%$ \\
\hline
\end{tabular}

* or equal

\subsection{Deriving Timing Decisions}

Combining static weights gained by expert judgments with market indicator time series is used to build a finacial crisis prediction model, which will be used to determine a market timing strategy. The basic idea is to rely on certain thresholds of the computed financial crisis probability to decide whether investing in the market index is profitable or not.

\subsubsection{Financial Crisis Probability}

Historical data sets for all market indicators are analyzed and individual quantiles for every indicator are computed. Allocation of single values to different quantiles is necessary to receive comparable and interpretable evaluations over time. The cumulative distribution of every market indicator is divided into 20 quantiles. Market indicators are supposed to increase financial crisis chances when their value is extraordinary (Section 3.1), that induces that focusing on high value quantiles is necessary.

These quantiles imply a score for the market indicator by using the rule from Table 3, which Niemira and Saaty (2004) call the signaling technique for evaluating incoming information on the scale 1-9. The original idea of the signaling technique was introduced as an alternative to regression, where the signal approach should provide diagnostic and predictive content, see Goldstein, Kaminsky and Reinhart (2000).

After every point in time $t(t=1, \ldots, T)$ is assigned with the derived score for the corresponding market indicator value, the weighted overall score in $s_{\text {total }, t}$ is computed by using the weights $w_{i}$ derived by the ANP model and the scores $s_{i, t}$ of the indicators $i$. 


$$
s_{\text {total }, t}=\sum_{i} w_{i} s_{i, t}, \quad i=1, \ldots, 8
$$

where $i$ is an index for the eight market indicators.

The maximum of $s_{\text {total,t }}$ equals 9, since the weights sum up to 1 and the maximal score is 9 for every indicator. In order to receive an interpretable probability value it is necessary to divide (1) by nine.

$$
p_{t}=\frac{s_{\text {total }, t}}{\max (\text { Scorevalue })}=\frac{\sum_{i} w_{i} s_{i, t}}{9}
$$

These probabilities for all $T$ observed points in time deliver a time series where on the one hand absolute values of financial crisis probability $p_{t}$ are of note and on the other hand changes $\delta_{t}=p_{t}-p_{t-1}$ from $t-1$ to $t$ are of interest to interpret the crisis probability.

\subsubsection{Thresholds}

It is incidental to define thresholds for the absolute value and the gain of the financial crisis probability $p_{t}$ to derive rules for the market timing strategy. These thresholds define whether switching to cash or short position is necessary. Different thresholds and their combinations define different scenarios of market timing. After inspecting the data, thresholds of financial crisis probability and its changes from one period to another are determined:

- probability $p_{t}$ of $25 \%$ to $70 \%$ in steps of $5 \%$, i.e. 10 different thresholds

- increase of probability $\delta_{t}$ of $5 \%$ to $20 \%$ in steps of $2,5 \%$, i.e. 7 different thresholds

The combination of different thresholds delivers 70 different scenarios to create 70 rules for our market timing strategies. That means, every strategy is based on a unique combination of (a) financial crisis probability and (b) financial crisis probability change thresholds, which induce switching to other investments.

\subsection{Inference}

Dangers of data snooping have long been recognized as serious problem of empirical studies in finance cf. for instance Lo and MacKinlay (1990), Brock, Lakonishok and LeBaron (1992) and Ferson, Sarkissian and Simin (2003). As we are investigating a total of 70 timing rules, a robust methodology to avoid spurious statistical inference due to data snooping is needed. Thus we employ the "Reality Check" (RC) by White (2000) and the test for superior predictive ability (SPA) introduced by Hansen (2005). Both procedures allow for intensive search for models while ensuring that the obtained results are robust and not a result of mere chance. Both procedures build on the work of Diebold and Mariano (1995) and West (1996) and will briefly be outlined in this section. We refer the reader to the articles of White (2000) and Hansen (2005) for a rigorous derivation of the procedures described below.

The RC tests the null hypothesis that the best model does not have superior predictive ability over the benchmark, while taking into account the full set of models, against the alternative that the best model has superior predictive ability. The test is based on the $l \times 1$ performance statistic:

$$
\overline{\mathbf{f}}=\frac{1}{n} \sum_{t=R}^{T} \hat{\mathbf{f}}_{t+1}
$$

where $l$ is the number of timing rules, $n$ is the number of prediction periods indexed from $R$ through $T$

so that $T=R+n-1$. $\hat{\mathbf{f}}_{t+1}=f\left(\mathbf{Z}_{t}, \hat{\boldsymbol{\beta}}_{t}\right)$ is the performance measure, where $\mathbf{Z}_{t}$ is a matrix, which contains a vector of dependent variables and a vector of predictor variables. $\hat{\boldsymbol{\beta}}_{t}$ is a vector of estimated parameters. 
It is assumed that these parameters satisfy the conditions of Diebold and Mariano (1995) and West (1996), so that parameter uncertainty vanishes asymptotically. In our case there are no estimated parameters, so that we do not have to verify, that the conditions for asymptotic irrelevance are met.

We use the returns generated from the $l$ timing rules as a performance measure. In the full sample from 1994-2008 $n=5479$ and $l=70$. For a timing rule $k$, we choose the following form for $f_{k, t+1}$ :

$$
f_{k, t+1}=\ln \left[1+\left(\frac{S_{t+1}-S_{t}}{S_{t}} X_{k}\left(\mathbf{Z}_{t}, \boldsymbol{\beta}_{k}\right)-\frac{S_{t+1}-S_{t}}{S_{t}} X_{0}\left(\mathbf{Z}_{t}, \boldsymbol{\beta}_{0}\right)\right)\right], \quad k=1, \ldots, l
$$

where $\mathbf{Z}_{t}$ consists of the predictor variables as described in Section 3.1, $S_{t}$ is the price of the S\&P index at time $t$ and $X_{k}$ and $X_{0}$ are "timing functions", which take on the value 1 for "invest in the stock market" and 0 for "hold cash" or -1 for "go short". With the performance statistic, we will test whether there exists a timing rule that delivers superior performance over a simple buy-and-hold strategy. Formally, the null states as,

$$
H_{0}: \max _{k=1, \ldots, l}\left\{E\left(f_{k}\right)\right\} \leq 0 .
$$

If the null can be rejected, it has been established that there exists a timing rule that leads to superior performance over a simple buy-and-hold strategy. It has been shown by White (2000) that under weak assumptions about the stationarity, dependence structure and moments of $\hat{\mathbf{f}}_{t}$ the distribution of the test statistic can be obtained by application of the stationary bootstrap of Politis and Romano (1994) as follows. In step 1 , we generate a resample of $\left\{f_{k, t}\right\}_{t=R}^{t=T}$ for each timing rule $k=1, \ldots, l$ by drawing (geometrically distributed) blocks from the observed return series, with mean block length $1 / q$. We shall denote the resampled series by $f_{k, t, j}^{*}$, where the subscript $j$ indicates the $j$-th repetition of the bootstrap. We will repeat the process $J$ times. In step 2, we compute the mean of the bootstrapped return series, $\bar{f}_{k, j}^{*}=n^{-1} \sum_{t=R}^{T} f_{k, t, j}^{*}, \forall k=1, \ldots, l$. In step 3 , we compute the following statistics

$$
\begin{gathered}
V_{R C}=\max _{k=1, \ldots, l}\left\{\sqrt{n} \bar{f}_{k}\right\}, \\
V_{R C, j}^{*}=\max _{k=1, \ldots, l}\left\{\sqrt{n}\left(\bar{f}_{k, j}^{*}-\bar{f}_{k}\right)\right\}, \quad j=1, . ., J
\end{gathered}
$$

We then compare $V_{R C}$ with the quantiles of $V_{R C, j}^{*}$. Thus, a $p$-value of the RC is given by

$$
p_{R C}=\sum_{j=1}^{J} \frac{1_{V_{R C, j}^{*}>V_{R C}}}{J},
$$

where $1_{\{\cdot\}}$ denotes the indicator function. In our empirical analysis we set $J=1000$ and choose a smoothing parameter of $q=0.5$. (Hansen, 2005) proposes some refinements of the RC that lead to more power in most cases. The SPA is very similar to the RC, yet it includes some refinements that can improve power in many conditions. The SPA makes use of the following studentized test statistic

$$
V_{S P A}=\max \left[\max _{k=1, . ., l} \frac{\sqrt{n} \bar{f}_{k}}{\hat{\sigma}_{k}}, 0\right]
$$

where $\hat{\sigma}_{k}^{2}$ is a consistent estimate of $\sigma_{k}^{2}=\operatorname{var}\left(\sqrt{n} \bar{f}_{k}\right)$. We will employ the estimator given in (Hansen, 2005). He also suggests to invoke a different null distribution, which is based on $N(\hat{\boldsymbol{\mu}}, \hat{\mathbf{\Omega}})$, where $\hat{\boldsymbol{\Omega}}$ denotes a consistent estimate of the asymptotic covariance matrix of $\overline{\mathbf{f}}$ and $\hat{\boldsymbol{\mu}}$ is an estimate for $E\left(\mathbf{f}_{t}\right)$. (Hansen, 2005) advocates the use of the following estimator 


$$
\hat{\mu}_{\mathrm{k}}=\overline{\mathrm{f}}_{\mathrm{k}} 1_{\left\{\sqrt{\mathrm{n}}\left(\overline{\mathrm{f}}_{\mathrm{k}} / \hat{\sigma}_{\mathrm{k}}\right) \leq-\sqrt{2 \ln \ln \mathrm{n}}\right\}} .
$$

(Hansen, 2005) shows by choosing this estimator, the irrelevant models do not influence the distribution of the test statistic asymptotically. This is done by applying the law of the iterated logarithm, which ensures that $\frac{\sqrt{n} \bar{f}_{k}-\mu_{k}}{\sigma_{k}}$ stays within certain bounds with probability 1 asymptotically. The implementation of the SPA is also very similar to the implementation of the RC. In step 1 , we generate a resample of $\left\{f_{k, t}\right\}_{t=R}^{t=T}$ for each timing rule $k=1, \ldots, l$ by drawing (geometrically distributed) blocks from the observed return series. We shall denote the resampled series $\left\{f_{k, t, j}^{*}\right\}$, where the subscript $j$ indicates the $j$-the repetition of the bootstrap. We will repeat the process $J$ times. In step 2, we compute $Z_{k, t, j}^{*}=f_{k, t, j}^{*}-\bar{f}_{k} 1_{\left\{\sqrt{n}\left(\bar{f}_{k} / \hat{\sigma}_{k}\right) \leq-\sqrt{2 \ln \ln \}}\right.} \forall k=1, \ldots, l, t=R, \ldots, T$. In step 3 , we compute the following statistics

$$
\begin{gathered}
V_{S P A}=\max \left[\max _{k=1, . . l} \frac{\sqrt{n} \bar{f}_{k}}{\hat{\sigma}_{k}}, 0\right] \\
V_{S P A, j}^{*}=\max \left[\max _{k=1, . .,} \frac{\sqrt{n} \bar{Z}_{k, j}^{*}}{\hat{\sigma}_{k}}, 0\right], \quad j=1, . ., J
\end{gathered}
$$

where $\bar{Z}_{k, j}^{*}=n^{-1} \sum_{t=R}^{T} Z_{k, t, j}$. We then compare $V_{S P A}$ with the quantiles of $V_{S P A, j}^{*}$. Thus, a $p$-value of the SPA is given by

$$
p_{S P A}=\sum_{j=1}^{J} \frac{1}{1_{V_{S P A, j}^{*}}^{*}>V_{S P A}}
$$

\section{Empirical Results}

The timing model described in Section 3.4 is used to determine rules for switching to an alternative investment rather than holding the S\&P 500, which will be called Long in this article. Consider two alternatives, annual interest of $4 \%$ called cash and entering a short position called short.

In times of fast market changes and financial instability, we focus on timing decision derived from daily observations. We focus on daily timing decision as this seems appropriate for the market dynamics today. Additionally, we present the results for weekly and monthly timing decisions.

Historical data analysis of market indicators is done from 1994 to 2008. After combining the results of this analysis with the weights from expert judgment we received the financial crisis probability, described in Section 3.4.1 for every day during these 15 years. Using the thresholds from Section 3.4.2 to create timing strategies lead to remarkable results, either in long-cash and long-short investments.

\subsection{Long-Cash}

Switching from stock index investments to cash during unstable times is less risky than entering a short position to avoid swings and receive a constant return. In order to keep the model simple, a fixed annual interest of $4 \%$ is used during the whole period of observation.

Table 4 contains an overview of the general performance of the ANP based market timing strategies. The results of daily strategies are notably, since $76 \%$ gain higher return than the basic buy and hold strategy investing in the S\&P 500. On average, even with the few underperforming rules, the annual return is 4.08\% higher during all the time from the beginning of 1994 till the end of 2008. 
Table 4: Overview Long-Cash Timing Strategies

\begin{tabular}{|l|c|c|c|}
\hline Summary Statistics & Day & Week & Month \\
\hline Rules with good performance $^{*}$ & 57 & 49 & 61 \\
\hline Rules with poor performance $^{*}$ & 13 & 16 & 9 \\
\hline Average advantage per rule $^{*}$ & $4.08 \%$ & $0.87 \%$ & $1.32 \%$ \\
\hline
\end{tabular}

compared to Buy and Hold

The best market timing strategy is inspected more precisely in Table 5. In case of daily timing decisions, the best strategy uses thresholds of $30 \%$ for financial crisis probability and $17.5 \%$ or $20 \%$ for its change, where both models performed equal (weekly $25 \%$ and $10 \%$, monthly $35 \%$ and $10 \%$ ). Compared to a buy and hold strategy with an annual return of $4.50 \%$ we receive $14.40 \%$ when using this best daily model. Figure 2 shows the time series of buy and hold an the best timing strategy. Computing the ratio of cash positions, the strategy lead to an investment in interest in nearly $60 \%$ of the time. The interest investments outperformed in $60 \%$ of the time compared to the buy and hold return. On average a period of cash investment takes about 8 days with an average winning of $0.04 \%$ per day compared to the buy and hold strategy, that means after deciding to switch the investment from long to cash, the model stays in cash for 8 days on average with an average advantage of $0.32 \%$ during one cash period. Since switching from one investment to another causes transaction fees, we take care of this issue in 4.3. Additionally weekly and monthly results are also displayed, but not discussed here since we focus on daily strategies.

Table 5: Summary Long-Cash Timing Strategies

\begin{tabular}{|c|c|c|c|c|}
\hline Summary Statistics & Best Rule & Best Rule & Best Rule & Buy and Hold \\
\hline & Day & Week & Month & \\
\hline Annualized average return & $14.40 \%$ & $8.10 \%$ & $8.36 \%$ & $4.50 \%$ \\
\hline P-value & 0.031 & & & \\
\hline Total number of long or cash positions & 5479 & 783 & 181 & \\
\hline Total number of cash positions & 3266 & 699 & 132 & \\
\hline Number of winning cash positions ${ }^{*}$ & 1949 & 339 & 64 & \\
\hline Number of loosing cash positions ${ }^{*}$ & 1317 & 360 & 68 & \\
\hline $\begin{array}{l}\text { Average number of periods in cash } \\
\text { position }\end{array}$ & 7.97 & 11.85 & 4.55 & \\
\hline Average difference per cash position ${ }^{*}$ & $0.04 \%$ & $0.05 \%$ & $0.34 \%$ & \\
\hline
\end{tabular}

* compared to long

\subsection{Long-Short}

If a market timing model has good predictive ability, it should be possible to increase the returns by going short and not just holding cash. This strategy bears more risk but also more potential gains compared to the long-cash strategy. Table 6 summarizes the results of the long-short strategies for daily, weekly and monthly data.

In this case, our focus is on daily strategies also, for which $76 \%$ gain higher values than a buy and hold strategy. On average timing strategies produce an outperformance of 5.57\% in terms annual return during the observed period from 1994 to 2008. 
Table 6: Overview Long-Short Timing Strategies

\begin{tabular}{|l|l|l|l|}
\hline Summary Statistics & Day & Week & Month \\
\hline Rules with good performance $^{*}$ & 57 & 35 & 41 \\
\hline Rules with poor performance $^{*}$ & 13 & 31 & 29 \\
\hline Average advantage per rule $^{*}$ & $5.57 \%$ & $-0.28 \%$ & $0.36 \%$ \\
\hline
\end{tabular}

* compared to Buy and Hold

In Table 7 we display, the best rule in daily market timing uses thresholds of $30 \%$ for financial crisis probability and $17.5 \%$ (or $20 \%$, with equal results) for its change (weekly $35 \%$ and $17.5 \%$ or $20 \%$, monthly $35 \%$ and $12.5 \%$ ). An annualized average return of $19.24 \%$ is almost $15 \%$ higher than the buy and hold strategy. This means during the observed 15 years an outcome of $1400 \%$ instead of less than $200 \%$ can be created, Figure 2 illustrated these results. The timing strategy suggests short investments in $48 \%$ of the time, where $51 \%$ are effective. This leads to an average difference per short position of $0.07 \%$ which seems rather small, but in case of daily investments this creates a large effect. A period of short investments is about four days long on average. Accounting for transaction costs does not qualitatively change the results, we refer to section 4.3 for further computation.

Table 7: Summary Long-Short Timing Strategies

\begin{tabular}{|l|c|c|c|c|}
\hline Summary Statistics & Best Rule & Best Rule & Best Rule & Buy and Hold \\
\hline & Day & Week & Month & \\
\hline Annualized average return & $19.24 \%$ & $6.51 \%$ & $8.47 \%$ & $4.50 \%$ \\
\hline P-value & 0.068 & & & \\
\hline Total number of long or short positions & 5479 & 783 & 181 & \\
\hline Total number of short positions & 2650 & 670 & 134 & \\
\hline Number of winning short positions * & 1350 & 312 & 61 & \\
\hline Number of loosing short positions * & 1300 & 358 & 73 & \\
\hline $\begin{array}{l}\text { Average number of periods in short } \\
\text { position }\end{array}$ & 3.81 & 8.70 & 5.15 & \\
\hline Average difference per short position & & & & \\
\hline
\end{tabular}

* compared to long

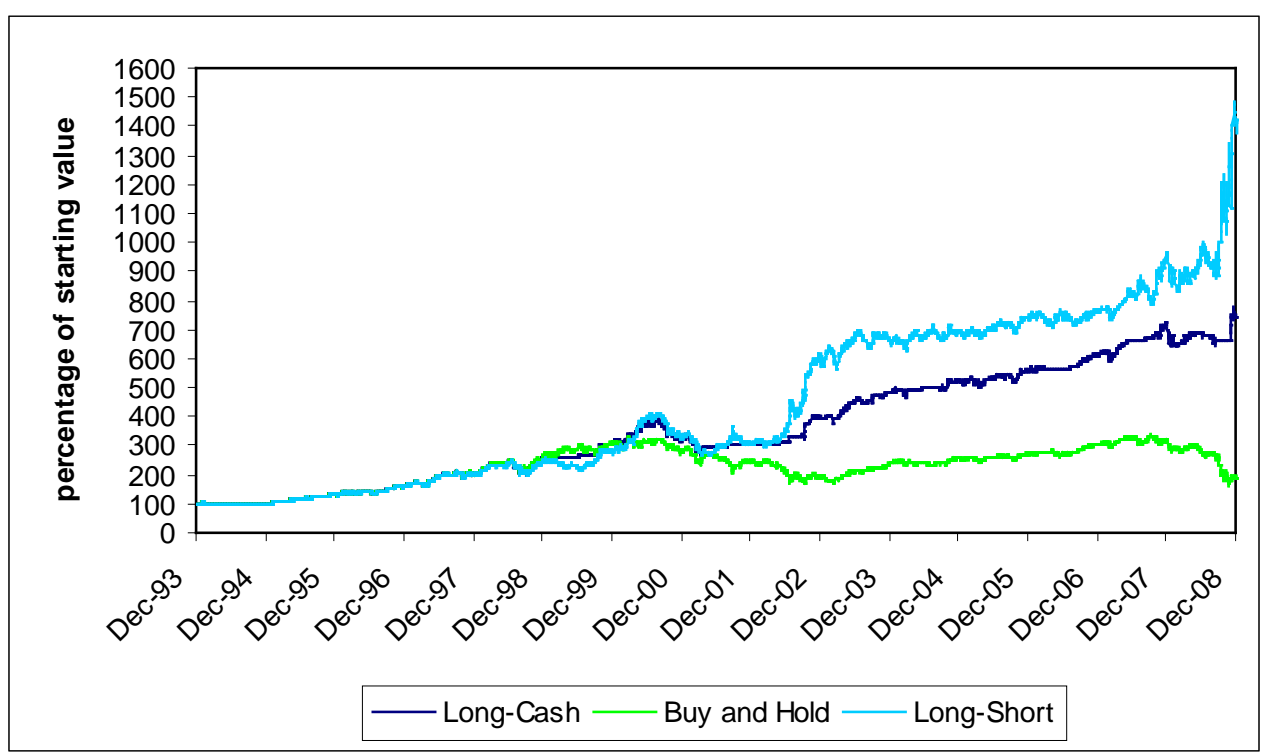

Figure 2: Buy and Hold vs. Best Timing Strategy 


\subsection{Transaction Fees}

Transaction fees are common in financial markets investments. To calculate the results of the market timing strategy with respect to these fees, we assume a fee of $0.05 \%$ per transaction taken from Fama and Blume (1966). The results for the best daily strategy of section 4 are nevertheless respectable.

The long-cash strategy gained an annualized average net return of $11.3 \%$ and the long-short strategy received $13.8 \%$, compared to the buy and hold strategy with $4.5 \%$ even the net performance of the timing strategy is remarkable.

\section{Conclusion}

In this paper we develop a stock market timing model based on the Analytical Hierarchy Process and apply it to the US stock market. Through application of the model, one could have obtained higher returns than through a buy and hold strategy in the backtested period. The proposed model may serve as a first step for asset managers and banks to put their timing decision in a structured framework.

In comparison with a regression model, our model has the advantage that it does not require vast amounts of data to yield reliable estimates. The expert judgments for the backtest of our model were obtained in June 2008, which may induce a possible bias in our backtest as these judgment are most likely to be timevarying also, we therefore suggest to use our model with these judgment for prediction in the near future. In order to increase robustness we should ask experts of financial markets periodically and then update the judgments and use these new judgments for further predictions until the judgments are updated again.

Another issue that should be addressed in future research is the integration of market indicators that are observed at different frequencies. A feasible solution to this problem could provide a bridge to include macro indicators which are usually observed at lower frequencies and also have a tendency to have a more inert effect on the objective.

\subsection{Expert Judgments}

\section{APPENDIX}

Table 8: Judgment Matrices

\begin{tabular}{|l|c|c|c|c|}
\hline Financial Crisis & Interest Rates & Market Appraisal & Resources & Sentiment \\
\hline Interest Rates & 1 & $1 / 3$ & 4 & 4 \\
\hline Market Appraisal & 3 & 1 & 4 & 2 \\
\hline Resources & $1 / 4$ & $1 / 4$ & 1 & $1 / 2$ \\
\hline Sentiment & $1 / 4$ & $1 / 2$ & 2 & 1 \\
\hline
\end{tabular}

\begin{tabular}{|l|c|c|}
\hline Resources & Financial Crisis & Resources \\
\hline Financial Crisis & 1 & 9 \\
\hline Resources & $1 / 9$ & 1 \\
\hline
\end{tabular}

\begin{tabular}{|l|c|c|}
\hline Market Appraisal & Interest Rates & Trading Activities \\
\hline Interest Rates & 1 & 3 \\
\hline Trading Activities & $1 / 3$ & 1 \\
\hline
\end{tabular}

\begin{tabular}{|l|c|c|}
\hline Crisis & Credit Spread & Term Spread \\
\hline Credit Spread & 1 & 6 \\
\hline Term Spread & $1 / 6$ & 1 \\
\hline
\end{tabular}

\begin{tabular}{|l|c|c|}
\hline Crisis & SPGSCI & Oil \\
\hline SPGSCI & 1 & $1 / 3$ \\
\hline Oil & 3 & 1 \\
\hline
\end{tabular}

\begin{tabular}{|l|c|c|}
\hline Crisis & PER & Implied Volatility \\
\hline PER & 1 & 6 \\
\hline Implied Volatility & $1 / 6$ & 1 \\
\hline
\end{tabular}

\begin{tabular}{|l|c|c|}
\hline Implied Volatility & PCR & Trade Volume \\
\hline PCR & 1 & $1 / 4$ \\
\hline Trade Volume & 4 & 1 \\
\hline
\end{tabular}

\subsection{Supermatrices}

Table 9: Unweighted Supermatrix

\begin{tabular}{|l|l|l|l|l|l|l|l|l|l|l|}
\hline & Crisis & $\begin{array}{c}\text { No } \\
\text { Crisis }\end{array}$ & $\begin{array}{c}\text { Credit } \\
\text { Spread }\end{array}$ & $\begin{array}{c}\text { Term } \\
\text { Spread }\end{array}$ & $\begin{array}{c}\text { Implied } \\
\text { Volatility }\end{array}$ & PER & SPGSCI & Oil & PCR & $\begin{array}{c}\text { Trade } \\
\text { Volume }\end{array}$ \\
\hline Crisis & 0 & 0 & 0.9 & 0.9 & 0.9 & 0.9 & 0.9 & 0.9 & 0 & 0 \\
\hline
\end{tabular}




\begin{tabular}{|l|l|l|l|l|l|l|l|l|l|l|}
\hline No Crisis & 0 & 0 & 0.1 & 0.1 & 0.1 & 0.1 & 0.1 & 0.1 & 0 & 0 \\
\hline $\begin{array}{l}\text { Credit } \\
\text { Spread }\end{array}$ & 0.86 & 0.86 & 0 & 1 & 0 & 1 & 0 & 0 & 0 & 0 \\
\hline $\begin{array}{l}\text { Term } \\
\text { Spread }\end{array}$ & 0.14 & 0.14 & 0 & 0 & 0 & 0 & 0 & 0 & 0 & 0 \\
\hline $\begin{array}{l}\text { Implied } \\
\text { Volatility }\end{array}$ & 0.14 & 0.14 & 0 & 0 & 0 & 0 & 0 & 0 & 1 & 1 \\
\hline PER & 0.86 & 0.86 & 0 & 0 & 0 & 0 & 0 & 0 & 0 & 0 \\
\hline SPGSCI & 0.25 & 0.25 & 0 & 0 & 0 & 0 & 0 & 1 & 0 & 0 \\
\hline Oil & 0.75 & 0.75 & 0 & 0 & 0 & 0 & 1 & 0 & 0 & 0 \\
\hline PCR & 0.5 & 0.5 & 0 & 0 & 0.2 & 0 & 0 & 0 & 0 & 0 \\
\hline $\begin{array}{l}\text { Trade } \\
\text { Volume }\end{array}$ & 0.5 & 0.5 & 0 & 0 & 0.8 & 0 & 0 & 0 & 0 & 0 \\
\hline
\end{tabular}

Table 10: Weighted Supermatrix

\begin{tabular}{|l|l|l|l|l|l|l|l|l|l|l|}
\hline & Crisis & $\begin{array}{l}\text { No } \\
\text { Crisis }\end{array}$ & $\begin{array}{c}\text { Credit } \\
\text { Spread }\end{array}$ & $\begin{array}{c}\text { Term } \\
\text { Spread }\end{array}$ & $\begin{array}{c}\text { Implied } \\
\text { Volatility }\end{array}$ & PER & SPGSCI & Oil & PCR & $\begin{array}{c}\text { Trade } \\
\text { Volume }\end{array}$ \\
\hline Crisis & 0 & 0 & 0.9 & 0.45 & 0.45 & 0.45 & 0.81 & 0.81 & 0 & 0 \\
\hline No Crisis & 0 & 0 & 0.1 & 0.05 & 0.05 & 0.05 & 0.09 & 0.09 & 0 & 0 \\
\hline $\begin{array}{l}\text { Credit } \\
\text { Spread }\end{array}$ & 0.24 & 0.24 & 0 & 0.5 & 0 & 0.5 & 0 & 0 & 0 & 0 \\
\hline $\begin{array}{l}\text { Term } \\
\text { Spread }\end{array}$ & 0.04 & 0.04 & 0 & 0 & 0 & 0 & 0 & 0 & 0 & 0 \\
\hline $\begin{array}{l}\text { Implied } \\
\text { Volatility }\end{array}$ & 0.08 & 0.08 & 0 & 0 & 0 & 0 & 0 & 0 & 1 & 1 \\
\hline PER & 0.51 & 0.51 & 0 & 0 & 0 & 0 & 0 & 0 & 0 & 0 \\
\hline SPGSCI & 0.03 & 0.03 & 0 & 0 & 0 & 0 & 0 & 0.1 & 0 & 0 \\
\hline Oil & 0.08 & 0.08 & 0 & 0 & 0 & 0 & 0.1 & 0 & 0 & 0 \\
\hline PCR & 0.01 & 0.01 & 0 & 0 & 0.1 & 0 & 0 & 0 & 0 & 0 \\
\hline $\begin{array}{l}\text { Trade } \\
\text { Volume }\end{array}$ & 0.01 & 0.01 & 0 & 0 & 0.4 & 0 & 0 & 0 & 0 & 0 \\
\hline
\end{tabular}

Table 11: Limit Supermatrix

\begin{tabular}{|l|l|l|l|l|l|l|l|l|l|l|}
\hline & Crisis & $\begin{array}{l}\text { No } \\
\text { Crisis }\end{array}$ & $\begin{array}{c}\text { Credit } \\
\text { Spread }\end{array}$ & $\begin{array}{c}\text { Term } \\
\text { Spread }\end{array}$ & $\begin{array}{l}\text { Implied } \\
\text { Volatility }\end{array}$ & PER & SPGSCI & Oil & PCR & $\begin{array}{c}\text { Trade } \\
\text { Volume }\end{array}$ \\
\hline Crisis & 0.36 & 0.36 & 0.36 & 0.36 & 0.36 & 0.36 & 0.36 & 0.36 & 0.36 & 0.36 \\
\hline No Crisis & 0.04 & 0.04 & 0.04 & 0.04 & 0.04 & 0.04 & 0.04 & 0.04 & 0.04 & 0.04 \\
\hline $\begin{array}{l}\text { Credit } \\
\text { Spread }\end{array}$ & 0.21 & 0.21 & 0.21 & 0.21 & 0.21 & 0.21 & 0.21 & 0.21 & 0.21 & 0.21 \\
\hline $\begin{array}{l}\text { Term } \\
\text { Spread }\end{array}$ & 0.02 & 0.02 & 0.02 & 0.02 & 0.02 & 0.02 & 0.02 & 0.02 & 0.02 & 0.02 \\
\hline $\begin{array}{l}\text { Implied } \\
\text { Volatility }\end{array}$ & 0.08 & 0.08 & 0.08 & 0.08 & 0.08 & 0.08 & 0.08 & 0.08 & 0.08 & 0.08 \\
\hline PER & 0.2 & 0.2 & 0.2 & 0.2 & 0.2 & 0.2 & 0.2 & 0.2 & 0.2 & 0.2 \\
\hline SPGSCI & 0.01 & 0.01 & 0.01 & 0.01 & 0.01 & 0.01 & 0.01 & 0.01 & 0.01 & 0.01 \\
\hline Oil & 0.03 & 0.03 & 0.03 & 0.03 & 0.03 & 0.03 & 0.03 & 0.03 & 0.03 & 0.03 \\
\hline PCR & 0.01 & 0.01 & 0.01 & 0.01 & 0.01 & 0.01 & 0.01 & 0.01 & 0.01 & 0.01 \\
\hline $\begin{array}{l}\text { Trade } \\
\text { Volume }\end{array}$ & 0.04 & 0.04 & 0.04 & 0.04 & 0.04 & 0.04 & 0.04 & 0.04 & 0.04 & 0.04 \\
\hline
\end{tabular}

\section{REFERENCES}

Breen, W. \& Glosten, L.R. \& Jagannathan, R. (1989). Economic Significance of Predictable Variations in Stock Index Returns. Journal of Finance, 44, 1177-1189.

Brock, W. \& Lakonishok, J. \& LeBaron, B. (1992). Simple Technical Trading Rules and the Stochastic Properties of Stock Returns. Journal of Finance, 47, 1731-1764.

Campbell, J.Y. (1987). Stock Returns and the Term Structure. Journal of Financial Economics, 18, 373- 
399.

Campbell, J.Y.. \& Shiller, R.J. (1988). Stock Prices, Earnings, and Expected Dividends. Journal of Finance, 43, 661-676.

Campbell, J.Y.. \& Shiller, R.J. (1988). The Dividend-Price Ratio and Expectations of Future Dividends and Discount Factors. Review of Financial Studies, 1, 195-228.

Campbell, J.Y.. \& Shiller, R.J. (1998) Valuation and the Long-Run Stock Market Outlook. Journal of Portfolio Management, 24, 11-26.

Campbell, J.Y.. \& Shiller, R.J. (2001). Valuation and the Long-Run Stock Market Outlook: An Update. NBER Working Paper, 8221, National Bureau of Economic Research.

Christoffersen, P.F. \& Diebold, F.X.. (2006). Financial Asset Returns, Direction-of-Change Forecasting, and Volatility Dynamics. Management Science, 52, 1273-1287.

Copeland, M.M. \& Copeland, T.E. (1999). Market timing: Style and size rotation using the VIX. Financial Analysts Journal, 55, 73-81.

Diebold, F.X. \& Mariano, R.S. (1995). Comparing Predictive Accuracy. Journal of Business and Economic Statistics, 13, 253-263.

Fama, E.F. \& Blume, M.E. (1966). Filter Rules and Stock-Market Trading. Journal of Business, 39, 226241.

Fama, E.F. \& French, K.R. (1989). Business Conditions and Expected Returns on Stocks and Bonds. Journal of Financial Economics, 25, 23-49.

Fama, E.F. \& French, K.R. (1988) Dividend Yields and Expected Stock Returns. Journal of Financial Economics, 2, 3-27.

Ferson, W.E. \& Sarkissian, S. and Simin, T.T. (2003). Spurious Regressions in Financial Economics?. Journal of Finance, 58, 1393-1413.

Fisher, K.L. \& Statman, M.. (2000). Investor Sentiment and Stock Returns. Financial Analysts Journal, $56,16-23$.

Fisher, K.L. \& Statman, M.. (2006). Market Timing at Home and Abroad. Journal of Investing, Summer, 19-27.

Fisher, K.L. \& Statman, M.. (2006). Market Timing in Regressions and Reality. Journal of Financial Research, 29, 293-304.

French, K.R. \& Schwert, G.W. \& Stambaugh, R.F. (1987). Expected Stock Returns and Volatility. Journal of Financial Economics, 19, 3-29.

Goldstein, M. \& Kaminsky, G. L. \& Reinhart, C.M. (2000). Assesing financial vulnerability: An early warning system for emerging markets.

Hansen, P. R. (2005). A Test for Superior Predictive Ability. Journal of Business and Economic Statistics, 
23, 365-380.

Harker, P. T. and Vargas, L.G. (1987). The Theory of Ratio Scale Estimation: Saaty's Analytic Hierarchy Process. Management Science, 33, 1383-1403.

Lo, A.W. and A. Craig MacKinlay. (1990) Data-Snooping Biases in Tests of Financial Asset Pricing Models. Review of Financial Studies, 3, 431-467.

Merton, R.C. (1980). On Estimating the Expected Return on the Market: An Exploratory Investigation. Journal of Financial Economics, 8, 323-361.

Mishkin, F. S. (1990). What Does the Term Structure Tell Us about Future Inflation?. Journal of Monetary Economics, 25, 77-95.

Niemira, M.P. and Saaty, T. L. (2004). An Analytic Network Process model for financial-crisis forecasting. International Journal of Forecasting, 20, 573-587.

Politis, D.N. and Romano, J.P. (1994). The Stationary Bootstrap. Journal of the American Statistical Association, 89, 1303-1313.

Prather, L. \& Bertin, W.J. (1997). Simple and Effective Trading Rule for Individual Investors. Financial Services Review, 6, 285-294.

Prather, L. \& Bertin, W.J. (1998). The Implication of Discount Rate Changes for Market Timing. Review of Financial Economics, 7, 21-33.

Saaty, T. L. (1977). A Scaling Method for Priorities in Hierarchical Structures. Journal of Mathematical Psychology, 15, 234-281.

Saaty, T. L. The Analytic Hierarchy Process. McGraw-Hill, NewYork, 1980.

Saaty, T. L. The Analytic Network Process: Dependence and Feedback in Decision Making (Part 1) Theory and Validation Examples. 2004.

Saaty, T. L. and Vargas, L.G. Decision Making With the Analytic Network Process: Economic, Political, Social and Technological Applications with Benefits, Opportunities, Costs and Risks. Springer Science+Business Media, New York, 2006.

Pu Shen (2003). Market Timing Strategies That Worked. Journal of Portfolio Management, 29, 57-68.

Shiller, R.J. (1984). Stock Prices and Social Dynamics. Brookings Papers on Economic Activity, 2, 457498.

Shilling, J.D. (1992). Market Timing: Better Than a Buy-and-Hold Strategy. Financial Analysts Journal, 48, 46-50.

West, K.D. (1996). Asymptotic Inference about Predictive Ability. Econometrica, 64, 1067-1084.

White, H. (2000) A Reality Check for Data Snooping. Econometrica, 68, 1097-1126. 